\title{
Barriers to and Enablers of Implementation of High-Value Interventions by Renal Pharmacists: A Qualitative Study Informed by the Theoretical Domains Framework
}

\author{
William Nevers, Alice Ratcheva, Kate Boutin, Sean K Gorman, Richard Slavik, and Natalie Lesko
}

\begin{abstract}
Background: Previous studies have shown that patients with chronic kidney disease who are followed by a renal clinical pharmacist have improved clinical outcomes. In 2016, a consensus list of quality indicator drug therapy problems (QI-DTPs) was developed by renal clinical pharmacists to help prioritize which renal patients should receive interventions. Before QI-DTP interventions can be implemented in clinical practice, barriers to and enablers of their use need to be identified, to allow development of strategies to overcome the barriers and apply the enablers.

Objective: To identify modifiable barriers to and enablers of implementation of renal QI-DTP interventions by renal clinical pharmacists.
\end{abstract}

Methods: In this exploratory qualitative descriptive study, one-on-one, semistructured, audio-recorded telephone interviews were conducted with renal clinical pharmacists to identify the barriers to and enablers of implementation of renal QI-DTP interventions. The interviews consisted of questions developed according to the Theoretical Domains Framework.

Results: Interviews were conducted with 13 renal pharmacists from across Canada. The main barriers to implementation of renal QI-DTP interventions that participants identified were knowledge gaps, prioritization, and nephrologist acceptance. The main enablers identified were training, colleague support, and better patient care.

Conclusion: Three barriers to and three enablers of implementation of renal QI-DTP interventions were identified. These barriers and enablers can be used to help with pharmacist education and to optimize the care that pharmacists provide to renal patients.

Keywords: quality indicator drug therapy problems, barrier, enabler, renal pharmacist, behaviour change

Can J Hosp Pharm. 2020;73(3):177-85

\section{RÉSUMÉ}

Contexte : Des études précédentes démontrent une amélioration des résultats cliniques de patients souffrant d'une maladie rénale chronique, qui sont suivis par un pharmacien clinicien en néphrologie. En 2016, des pharmaciens cliniciens en néphrologie ont mis au point une liste consensuelle des indicateurs de qualité des problèmes de pharmacothérapie (QI-DTP) pour les aider à prioriser les patients souffrant d'une insuffisance rénale, qui doivent subir une intervention. Avant de mettre en place ces QI-DTP en pratique clinique, on doit déterminer les éléments qui entravent et facilitent leur utilisation pour pouvoir élaborer des stratégies visant à surmonter les obstacles et à appliquer les éléments facilitateurs.

Objectif: Déterminer les éléments modifiables qui entravent et facilitent la mise en place des QI-DTP par les pharmaciens cliniciens en néphrologie lors d'interventions rénales.

Méthodes : Dans cette étude exploratoire, descriptive et qualitative, des entretiens téléphoniques individuels, semi-structurés et enregistrés ont été menés auprès de pharmaciens cliniciens en néphrologie pour déterminer les éléments qui entravent et facilitent la mise en place de QI-DTP lors d'interventions rénales. Les entretiens consistaient en des questions préparées selon le Theoretical Domains Framework.

Résultats : Les entretiens ont été menés auprès de 13 pharmaciens en néphrologie de partout au Canada. Les principaux éléments entravant la mise en place de QI-DTP lors d'interventions rénales déterminées par les participants étaient : le manque de connaissances, la priorisation et l'acception des néphrologues. Les principaux éléments facilitant la tâche étaient : la formation, le soutien des collègues et de meilleurs soins offerts aux patients.

Conclusion : Trois éléments entravant et trois éléments facilitant la mise en place de QI-DTP lors d'interventions rénales ont été déterminés. Ils peuvent être utilisés pour contribuer à la formation du pharmacien et pour optimiser les soins offerts aux patients qui souffrent d'insuffisance rénale.

Mots-clés : indicateur de la qualité des problèmes de pharmacothérapie, obstacle, facilitateur, pharmacien néphrologue, changement de comportement 


\section{INTRODUCTION}

7 he number of individuals with chronic kidney disease 1 (CKD) in Canada is about 2.4 million, and about one-third of these have stage 3 to $5 \mathrm{CKD}^{1}{ }^{1}$ On average, patients receiving hemodialysis take 10 to 12 medications per day, putting them at high risk of experiencing drug therapy problems (DTPs). ${ }^{2}$ A DTP is any undesirable event or risk experienced by the patient that involves drug therapy and prevents the patient from achieving the goals of therapy. ${ }^{3}$ Renal clinical pharmacists collaborate with other health care professionals on multidisciplinary teams to help prevent and resolve DTPs. ${ }^{4,5}$ Patients with CKD who receive care from a health care team that includes a renal clinical pharmacist experience reduced mortality, fewer hospital admissions, improved medication adherence, and fewer adverse effects from medications. ${ }^{5}$

However, the ratio of renal clinical pharmacists to patients who have $\mathrm{CKD}$ or need dialysis varies across Canada, and there are no consensus guidelines that recommend an appropriate ratio of pharmacists to patients in the renal care setting. ${ }^{6}$ This means that renal pharmacists may not have the capacity to identify and resolve all DTPs in all renal patients. As a result, in order to provide the most value to patients and the health care system, renal clinical pharmacists need to prioritize which patients they see and which of these patients will receive high-value interventions, that is, interventions most likely to improve patients' health outcomes. ${ }^{7,8}$

In 2016, a consensus list of quality indicator drug therapy problems (QI-DTPs) was developed by a group of renal clinical pharmacists to help renal pharmacists prioritize the patients who should receive direct patient care. ${ }^{9}$ Each QI-DTP intervention was developed by extracting strong recommendations from renal clinical practice guidelines published between 2010 and 2015 and identifying those that met the following criteria: is based on a prevalent and impactful complication of CKD, is supported by high-quality evidence (randomized controlled trial or metaanalysis), results in resolution of a DTP, and improves the quality of drug therapy. All candidate QI-DTP interventions meeting these criteria were reviewed by 18 Canadian renal clinical pharmacists, who used a Delphi process to reach consensus on which QI-DTP interventions would result in advancement of renal pharmacy practice and improve the quality of patient care. This process resulted in 17 consensus-based renal pharmacy QI-DTP interventions that renal clinical pharmacists could use to assist in prioritizing the patients to whom they provide care and the interventions they deliver.

The presence of QI-DTPs does not guarantee that pharmacists will implement the associated interventions in their practice. Published research has demonstrated that knowledge does not directly translate into behaviour and practice change; this discrepancy can be described as the know-do gap. ${ }^{10,11}$ Pharmacists do not always implement evidence-based best pharmacotherapy practices for various reasons, such as clinician-, patient-, and system-related factors. ${ }^{8,11-15}$ More specific to renal pharmacy, some renal pharmacists are not aware of evidence-based guidelines for clinical practice. ${ }^{16}$ It is essential to close the know-do gap with respect to renal QI-DTPs, to ensure that patients with renal disease who have prevalent and impactful drug therapy needs receive high-quality pharmaceutical care. There has been some research on the interventions that renal pharmacists should perform, but there are few high-quality studies that address the effects of such interventions in renal patients. ${ }^{17} \mathrm{~A}$ systematic review published in 2012 suggested that medication reviews, patient education, promotion of compliance, and protocol development would benefit renal patients and the renal care team, and would also confer cost savings. ${ }^{18}$ Barriers to the implementation of these interventions were lack of funding; lack of hospital administrator's approval; staff shortages; lack of academic training; relationships with physicians; and attitudes of pharmacists, patients, and the renal health care team. ${ }^{18}$ Enablers identified were access to information sources, consent from the care team, access to patient profiles, and having a full-time renal pharmacist on the team. ${ }^{18}$ The current study focuses on identifying specific barriers and enablers to implementing the 17 renal QI-DTP interventions that were systematically identified in the previous study. ${ }^{\text {? }}$

The design of implementation interventions aimed at closing the know-do gap requires a systematic approach that is both transparent and rooted in a validated theoretical framework. ${ }^{19}$ The Theoretical Domains Framework (TDF) is an evidence-based tool that can be used to identify barriers to and enablers of behaviour change in clinical practice. ${ }^{13,20}$ This validated tool was developed to identify psychological and organizational theory associated with health care providers' clinical behaviour change. ${ }^{13,20}$ The TDF consists of 14 domains covering the main factors that influence behaviour, specifically social influences, social and professional role and identity, knowledge, environmental context and resources, beliefs about capabilities, behavioural regulation, beliefs about consequences, skills, memory attention and decision processes, intentions, optimism, goals, emotion, and reinforcement. ${ }^{13,20}$

According to the TDF, there are 4 steps to developing a theory-informed implementation intervention: identifying the problem (who needs to do what activity differently), assessing the problems (finding barriers and enablers), developing possible solutions (which interventions could overcome the barriers and promote the enablers), and evaluating the intervention (measuring and understanding the behaviour change). ${ }^{13}$

The TDF approach to designing behaviour change interventions has been integrated into the Behavivour Change Wheel. The Behaviour Change Wheel is a tool that describes the behaviour of interest in terms of sources of capability, opportunity, and motivation (COM-B). According to the COM-B system, an individual must possess capability, motivation, and opportunity in order for behaviour change to occur. ${ }^{12}$ The 14 domains of the 
TDF have been independently mapped onto the COM-B segments. This is helpful for the design of future behaviour change interventions, because each source of behaviour outlined in the COM-B system has been linked to proven behaviour change interventions. Therefore, if barriers and enablers for a target behaviour are assessed using the TDF, they can be mapped to the COM-B system, which can then be used to select suitable behaviour change interventions to attempt to systematically change the behaviour.

The aim of this study was to identify barriers and enablers to implementing the renal QI-DTP interventions, as perceived by renal clinical pharmacists. The results of this study will inform future development and implementation of behaviour change interventions directed toward renal QI-DTPs, which will help to standardize practice and improve renal patient care.

\section{METHODS}

\section{Study Design, Sampling, and Setting}

This exploratory qualitative descriptive study was conducted by means of one-on-one, semistructured, audio-recorded telephone interviews with renal pharmacists. A convenience sample of renal pharmacists from across Canada was sought, including professionals from different provinces, with different levels of experience, working in a variety of practice settings. Potential participants were included if they were clinical pharmacists working in various renal settings (chronic kidney disease, hemodialysis, peritoneal dialysis) at tertiary, regional, or community hospitals across Canada. The specific inclusion criterion was spending more than $50 \%$ of their time providing direct patient care to adults with $\mathrm{CKD}$, with or without dialysis. Pharmacists who served as panelists in the study for developing renal QI-DTPs, participants who were unable to complete the interview before April 1, 2017, and those unable to communicate in English were excluded. Participants were recruited by the principal investigator (W.N.) using the Renal Pharmacist Network listserv (www.renalpharmacists.net). A brief message was posted to the listserv, inviting interested pharmacists to contact the principal investigator by email, supplying their phone number. All renal pharmacists who responded and met the inclusion criteria were included in the study, and an interview time was scheduled according to their availability. All participants provided written informed consent (signed consent forms sent by e-mail to the principal investigator). This study was approved by the Interior Health Authority Research Ethics Board. The study interviews were conducted between February 13 and February 28, 2017. Participants did not receive any compensation.

\section{Semistructured Interview Guide}

The interview guide used questions adapted from the 14 domains of the TDF to identify factors that influence behaviour change (see Appendix 1, available at https://www.cjhp-online.ca/ index.php/cjhp/issue/view/198/showToc). ${ }^{21,22}$ The interview guide was developed by 2 of the investigators (W.N., S.K.G.), and was then reviewed and edited as necessary by the other investigators, to improve the clarity and quality of the interview questions. These questions were open-ended and aimed to determine the factors affecting whether renal pharmacists would address renal QI-DTPs in their daily practice. There were 1 or 2 questions for each TDF domain, and follow-up prompts were included as needed to account for certain constructs of the TDF. The intention was to keep the interviews relatively short (20-30 min), so it was not possible to ask a series of specific questions for each QI-DTP. Instead, the questions were broad and encompassed all 17 of the renal QI-DTP interventions as a group, analogous to a group of recommendations from a clinical practice guideline. Demographic information was collected before each interview began. To minimize bias, all potential participants were asked whether they had any known or perceived conflicts of interest related to any of the renal QI-DTPs interventions; anyone who declared the existence of such a conflict of interest was excluded.

\section{Participant Orientation to Renal QI-DTP Interventions}

Three weeks before the interview, a 10-min slide presentation with voice-over was sent by e-mail to each participant, to provide background on the renal QI-DTP interventions, the purpose of the study, the study methods, and the interview process. Participants also received an electronic copy of the list of renal QI-DTP interventions. Participants were asked to confirm by e-mail that they had viewed the slide presentation. During this 3-week timeframe and throughout the study period, the principal investigator was available to answer questions from participants related to the research process.

\section{Data Collection}

All of the telephone interviews were conducted by a trained investigator (A.R.). The interviews were audio-recorded and transcribed verbatim.

\section{Data Analysis}

The audio-recorded interviews were anonymously transcribed and coded by the same investigator who conducted the interviews (A.R.) using NVivo 11 Starter for Windows software (QSR International Americas Ltd, Burlington, Massachusetts), and reflexive journaling was used to lend rigour and trustworthiness to the data. Two of the interviews were coded by a second investigator (W.N.) to check inter-rater reliability. The data were analyzed through a directed content analysis using the TDF. ${ }^{23}$ A coding guide adapted from previous literature was used to enable thematic and directed content analysis of participants' responses. $^{22}$ The coding guide (Appendix 2, available at 
https://www.cjhp-online.ca/index.php/cjhp/issue/view/198/ showToc) was agreed upon by members of the research team to ensure consistent coding. Codes reflected the 14 TDF domains (as listed above) and were categorized into themes to determine modifiable barriers and enablers to implementing the renal QI-DTP interventions into practice, as identified by the participants. Each participant response or applicable portion of a response was coded to the most appropriate of the $14 \mathrm{TDF}$ domains. The total number of times each TDF domain was matched to a participant response was captured. Direct quotes supporting the themes were extracted to strengthen the trustworthiness of the analysis. The responses corresponding to the TDF domains for knowledge, behavioural regulation, skills, and memory attention and decision processes were mapped to "capability" on the COM-B. The responses corresponding to the TDF domains for social influences and environmental context and resources were mapped to "opportunity", and the responses corresponding to the TDF domains for social and professional role and identity, beliefs about capabilities, beliefs about consequences, intentions, optimism, and goals were mapped to "motivation".

The investigator who performed the majority of the coding wrote in a reflexive journal, after coding each interview, to document thoughts about participants, questions, and responses.

\section{RESULTS}

Thirteen renal pharmacists from 6 Canadian provinces participated in this study, and all participants completed the full interview. The interview duration ranged from 19 to $34 \mathrm{~min}$. Relevant participant characteristics are reported in Table 1. Of note, most participants were female (9/13), the group was about evenly divided in terms of experience as a renal pharmacist (with about one-third in each of the 3 categories, for 1-5 years, 6-10 years, and 11 or more years of experience) and more than half (7/13) had completed a pharmacy practice residency or a postentry-to-practice doctor of pharmacy degree.

Twelve TDF domains were coded from the interviews; the emotion and reinforcement domains were not reflected by comments during the interviews and therefore were not coded. A total of 349 utterances were coded across these 12 TDF domains (Table 2). The 2 most frequently coded TDF domains were social influences (87 utterances) and environmental context and resources (53 utterances), whereas the 2 least frequently coded TDF domains (excluding the 2 domains with no coding) were optimism (3 utterances) and goals (1 utterance). Sample utterances for each domain are shown in Table 3.

\section{Barriers to Implementation of Renal QI-DTP Interventions}

Three themes were identified that reflected barriers to renal pharmacists' implementation of renal QI-DTP interventions

\section{Table 1. Participant Characteristics}

\begin{tabular}{lcc} 
Characteristic & \multicolumn{2}{c}{$\begin{array}{c}\text { No. (\%) of } \\
\text { Participants } \\
\boldsymbol{n}=\mathbf{1 3}\end{array}$} \\
\hline Sex, female & 9 & $(69)$ \\
\hline Province of practice & 1 & $(8)$ \\
British Columbia & 2 & $(15)$ \\
Alberta & 3 & $(23)$ \\
Manitoba & 5 & $(38)$ \\
Ontario & 1 & $(8)$ \\
Quebec & 1 & $(8)$ \\
Nova Scotia & & \\
Experience as a renal pharmacist & 5 & $(38)$ \\
1-5 years & 4 & $(31)$ \\
6-10 years & 4 & $(31)$ \\
$\geq 11$ years & & \\
Highest academic credential & 6 & $(46)$ \\
Bachelor of Science in Pharmacy & 3 & $(23)$ \\
Pharmacy Residency & 4 & $(31)$ \\
Post entry-to-practice PharmD & & \\
Patient subpopulation* & 7 & $(54)$ \\
CKD, all stages pre-dialysis & 9 & $(69)$ \\
ESRD, hemodialysis & 3 & $(23)$ \\
ESRD, peritoneal dialysis &
\end{tabular}

$\overline{C K D}=$ chronic kidney disease, $\mathrm{ESRD}=$ end-stage renal disease.

*The percentages sum to more than 100 because some respondents were involved with care for more than 1 patient subpopulation.

\section{Table 2. TDF Domains and Utterances}

\section{TDF Domain Code}

No. of Utterances

\begin{tabular}{lc}
\hline Social influences & 87 \\
Environmental context and resources & 53 \\
Beliefs about capabilities & 37 \\
Beliefs about consequences & 37 \\
Social/professional role and identity & 36 \\
Behavioural regulation & 26 \\
Skills & 23 \\
Knowledge & 20 \\
Intentions & 13 \\
Memory attention and decision processes & 13 \\
Optimism & 3 \\
Goals & 1 \\
Emotion & 0 \\
Reinforcement & 0 \\
Total utterances & 349 \\
\hline
\end{tabular}

TDF = Theoretical Domains Framework.

(Table 4). The themes for barriers reflected all 3 components of the COM-B system (capability, opportunity, and motivation).

From a capability perspective, some participants did not feel that they had sufficient knowledge of the renal QI-DTPs to perform high-priority interventions. For example, one participant stated, "When it comes to initiating intravenous iron therapy, I would probably like a little bit more training. I mean, I know the basics but I haven't actually initiated IV iron therapy on any pre-dialysis patients. It is done, but I think it's more commonly done in hemodialysis patients. I don't have experience with that" (Pharmacist 5). 


\section{Table 3 (Part 1 of 2). Participants' Direct Quotations}

\begin{tabular}{|c|c|c|}
\hline TDF Domain Code & $\begin{array}{c}\text { No. of } \\
\text { Participants* }\end{array}$ & Barrier \\
\hline Social influences & 13 & $\begin{array}{l}\text { I work with about } 13 \text { different nephrologists } \\
\text { and they all seem to do their own thing. So } \\
\text { these are excellent guidelines and it was great } \\
\text { to learn how rigorously they were came up } \\
\text { with ... but having said that, as a pharmacist, } \\
\text { we make a recommendation and then the } \\
\text { nephrologist sometimes decides to do their } \\
\text { own thing anyway. (Pharmacist 5) }\end{array}$ \\
\hline $\begin{array}{l}\text { Social and professional } \\
\text { role and identity }\end{array}$ & 13 & $\begin{array}{l}\text { The biggest barrier is our role in the clinic. It's } \\
\text { primarily nephrologist driven. So while we're } \\
\text { there to provide recommendations, it all goes } \\
\text { to the nephrologist and the nephrologist } \\
\text { determines what changes are made } \\
\text { primarily ... in this particular location. } \\
\text { (Pharmacist 5) }\end{array}$ \\
\hline Knowledge & 13 & $\begin{array}{l}\text { Well definitely I would have to brush up on } \\
\text { my knowledge of antihypertensive treatment } \\
\text { in renal patients, especially the ones who are } \\
\text { not yet on dialysis. I just find that there's a lot } \\
\text { of background that I don't know and I just } \\
\text { don't know where to start. (Pharmacist 2) }\end{array}$ \\
\hline
\end{tabular}
don't know where to start. (Pharmacist 2)

\begin{tabular}{lll}
\hline Environmental context & Main barriers are again time constraint, to \\
and resources & nephrologist availability. I mean you can text \\
& it, but sometimes it's easier to discuss it fully \\
because the nephrologist may not have all \\
the information in front of them. That would \\
probably be the 2 main barriers. I mean other \\
barriers ... I do have some responsibilities with \\
the central pharmacy. (Pharmacist 9)
\end{tabular}

\begin{tabular}{ll}
\hline Behavioural regulation & We have management algorithms for anemia \\
& $\begin{array}{l}\text { management ... so it's primarily nursing driven. } \\
\text { (Pharmacist 8) }\end{array}$
\end{tabular}
(Pharmacist 8)

\begin{tabular}{|c|c|c|}
\hline Beliefs about consequences & 12 & $\begin{array}{l}\text { I'm not sure that there is really a downside, } \\
\text { but I wonder if I were doing all these things, } \\
\text { that other things would be pushed aside and } \\
\text { maybe I would be focusing on these and not } \\
\text { seeing the patients as a whole ... Maybe it } \\
\text { would take away some of that holistic } \\
\text { approach. (Pharmacist 2) }\end{array}$ \\
\hline Skills & 11 & $\begin{array}{l}\text { When it comes to initiating intravenous iron } \\
\text { therapy, I would probably like a little bit more } \\
\text { training. I mean, I know the basics but I } \\
\text { haven't actually initiated IV iron therapy on } \\
\text { any pre-dialysis patients. It is done, but I think } \\
\text { it's more commonly done in hemodialysis } \\
\text { patients. I don't have experience with that. } \\
\text { (Pharmacist 5) }\end{array}$ \\
\hline
\end{tabular}

I think education is also an important one. So you have to have confidence when you want to make recommendations, and if you are making recommendations, you really need to be able to back it up with as much evidence as you can ... and so having the continuing education, knowing about the studies that have been done in the area, or the practice guidelines, that sort of thing. What'll help you to feel more confident when you're making the recommendations to other folks on the teams, I think that's an important part as well. (Pharmacist 3)

Yeah, I think human resources is certainly one, just literally having enough people to be able to review all the medical conditions ... see where there are issues, drug therapy issues ... and then be able to resolve them. (Pharmacist 3)

I'm fortunate in that it's not ... to integrate into my practice at all ... just because I'm dedicated to the hemodialysis, $100 \%$ clinical ... so I mean for me these quality indicators would not be ... none of them would be difficult for me to initiate. (Pharmacist 1)

We have some policies and procedures ... a lot of guidelines set up in place, we have them through the South Alberta Renal Program. They have lots of built-in policies on that kind of stuff. So they have a statin policy, they have a blood pressure policy, Aspirin [acetylsalicylic acid] and those types of preventative things. (Pharmacist 5) Oh, just job satisfaction. Feeling like we are actually ... affecting outcome. I think that's a big one. And not just kind of going through the motions. I think that maintaining your competence and your confidence helps a lot towards being happy with your job (Pharmacist 4). I stepped away and went to school for a couple years just so that I could develop these skills. I'm pretty comfortable implementing these QIs and again lucky that I have the support of the nephrology team so I can actually make changes. (Pharmacist 9) 
Table 3 (Part 2 of 2). Participants' Direct Quotations

\begin{tabular}{|c|c|c|c|}
\hline TDF Domain Code & $\begin{array}{c}\text { No. of } \\
\text { Participants* }\end{array}$ & Barrier & Enabler \\
\hline $\begin{array}{l}\text { Memory attention and } \\
\text { decision processes }\end{array}$ & 11 & NA & $\begin{array}{l}\text { I think it's on the monthly bloodwork, especially } \\
\text { in hemodialysis. Any time we are off target for } \\
\text { one of these QI-DTPs an intervention would be } \\
\text { welcome. It's a shared intervention I guess, with } \\
\text { the nephrologist ... but in this particular set-up } \\
\text { here, since the nephrologists aren't always there } \\
\text { our place as a leader in drug therapy } \\
\text { interventions are absolutely great to have. } \\
\text { (Pharmacist 7) }\end{array}$ \\
\hline Intentions & 10 & $\begin{array}{l}\text { Well, things like pharmacokinetic monitoring } \\
\text { and things that have to be done on that day } \\
\text { at that time would be higher priority and } \\
\text { these would be sort of, nice to improve if } \\
\text { possible. Might influence outcomes long term. } \\
\text { (Pharmacist 2) }\end{array}$ & $\begin{array}{l}\text { Well, when I'm in clinics, which is probably } 70 \% \\
\text { of the week, they are high priority, as the } \\
\text { pharmacist on the team. But when I'm not in } \\
\text { clinics, I'm not usually dealing with that, I'm just } \\
\text { preparing ... so I guess medium. (Pharmacist 5) }\end{array}$ \\
\hline Optimism & 3 & $\begin{array}{l}\text { Because when you talk about what applies to } \\
\text { a dialysis population then for sure, the way } \\
\text { funding is changing in Ontario right now ... } \\
\text { in the immediate pre-dialysis to dialysis } \\
\text { population, I'm not sure some of these } \\
\text { interventions are relevant. (Pharmacist 6) }\end{array}$ & $\begin{array}{l}\text { I agree that it's possible to integrate all of them. } \\
\text { In terms of accomplishing some of these } \\
\text { changes, it might take months. (Pharmacist 10) }\end{array}$ \\
\hline Goals & 1 & NA & $\begin{array}{l}\text { Yeah we have a bone mineral, anemia, med rec, } \\
\text { etc.... each has its own quality team within the } \\
\text { nephrology program. So within each quality } \\
\text { team, there are different projects with priority so } \\
\text { a lot of ... not all, but some of my focus for my } \\
\text { work is dictated by achieving the goals of the } \\
\text { program, and how I can help achieve those goals. } \\
\text { (Pharmacist 8) }\end{array}$ \\
\hline Emotion & 0 & NA & NA \\
\hline Reinforcement & 0 & NA & NA \\
\hline
\end{tabular}

$\overline{\mathrm{DTP}}=$ drug therapy problem, NA = not applicable, QI = quality improvement, TDF = Theoretical Domains Framework.

*The number of participants who mentioned the particular TDF domain code.

\section{Table 4. Barrier Themes*}

\begin{tabular}{ll}
$\begin{array}{l}\text { Category } \\
\text { Capability }\end{array}$ & $\begin{array}{l}\text { Theme } \\
\text { sufficient knowledge to perform high-priority } \\
\text { interventions. }\end{array}$ \\
\hline Opportunity & $\begin{array}{l}\text { Renal pharmacists are limited in their ability to } \\
\text { perform high-priority interventions by the } \\
\text { nephrologists with whom they work. }\end{array}$ \\
\hline Motivation & $\begin{array}{l}\text { Renal pharmacists do not consider the renal } \\
\text { Ql-DTP interventions to be the highest-priority } \\
\text { interventions. }\end{array}$ \\
QI-DTP = quality indicator drug therapy problem. \\
*Based on the Behaviour Change Wheel, a tool that describes the \\
behaviour of interest in terms of sources of capability, opportunity, \\
and motivation (COM-B). According to the COM-B system, an \\
individual must possess capability, motivation, and opportunity in \\
order for behaviour change to occur.12
\end{tabular}

The renal pharmacists who participated in this study did not consider the renal QI-DTP interventions to be the highestpriority interventions, which may underlie a motivation deficit pertaining to performing drug therapy interventions that have been proven to improve outcomes in these patients. For example, one participant stated, "Well, things like pharmacokinetic monitoring and things that have to be done on that day at that time would be higher priority and these would be sort of, nice to improve if possible. Might influence outcomes long term" (Pharmacist 2).
In terms of opportunity-related barriers, participants noted that they are limited in their ability to perform high-priority interventions by the nephrologists with whom they work. For example, one participant stated, "I work with about 13 different nephrologists and they all seem to do their own thing. So these are excellent guidelines and it was great to learn how rigorously they were came up with ... but having said that, as a pharmacist, we make a recommendation and then the nephrologist sometimes decides to do their own thing anyway" (Pharmacist 5).

\section{Enablers of Implementation of Renal QI-DTP Interventions}

Three themes were identified that reflected enablers of renal pharmacists' implementation of renal QI-DTP interventions (Table 5). One of the themes applied from the perspectives of both capability and motivation. According to this theme, participants who had received additional formal training, such as a pharmacy practice residency, felt more confident in performing high-priority interventions reflected in the QI-DTPs. For example, one participant stated, "I stepped away and went to school for a couple years just so that I could develop these skills. I'm pretty comfortable implementing these QIs and again lucky that I have the support of the nephrology team so I can actually make changes" (Pharmacist 9). 
Table 5. Enabler Themes*

\begin{tabular}{|c|c|}
\hline Category & Theme \\
\hline Capability & $\begin{array}{l}\text { Renal pharmacists who have received additional } \\
\text { training (residency, PharmD) feel more confident } \\
\text { in performing high-priority interventions. }\end{array}$ \\
\hline Opportunity & $\begin{array}{l}\text { Renal pharmacists can perform high-priority } \\
\text { interventions when they have support from } \\
\text { colleagues and nephrologists. }\end{array}$ \\
\hline Motivation & $\begin{array}{l}\text { 1. Renal pharmacists want their patients to } \\
\text { achieve the best health outcomes possible. } \\
\text { 2. Renal pharmacists who have received } \\
\text { additional training (residency, Pharm D) feel } \\
\text { more confident in performing high-priority } \\
\text { interventions. }\end{array}$ \\
\hline \multicolumn{2}{|c|}{$\begin{array}{l}\text { *Based on the Behaviour Change Wheel, a tool that describes the } \\
\text { behaviour of interest in terms of sources of capability, opportunity, and } \\
\text { motivation (COM-B). According to the COM-B system, an individual } \\
\text { must possess capability, motivation, and opportunity in order for } \\
\text { behaviour change to occur. }{ }^{12}\end{array}$} \\
\hline
\end{tabular}

A second motivation enabler theme was also identified, whereby renal pharmacists wanted their patients to achieve the best health outcomes possible. For example, one participant stated, "I think it's our role to actually identify areas where you would implement the QI ... to communicate to the other health care providers working with us what we would want to implement and why" (Pharmacist 1).

Finally, there was one enabler theme related to opportunity. Participants stated that they could perform high-priority interventions when they had support from colleagues and nephrologists. For example, one participant stated, "I suppose a lot of it has to do with your communication with your nephrology team. Over the years you get comfortable with the people working on your team ... the nurses, nephrologist, etc. I think part of being able to do all of these interventions is having a trust and a comfort level with the team that you work with" (Pharmacist 3).

\section{DISCUSSION}

Previous studies have explored interventions that renal pharmacists can perform to improve patient outcomes. ${ }^{17,18}$ For example, a 2012 study looked at pharmacists' interventions in the management of patients with chronic kidney disease, but the authors did not specifically examine which interventions had the most value for renal pharmacists to perform. ${ }^{18}$

Since there is no established standard of practice for renal clinical pharmacists in Canada, the set of 17 previously determined renal QI-DTP interventions may help pharmacists prioritize the patients they care for and the DTPs on which they intervene to improve the quality of care. ${ }^{9}$

This study was unique in using a framework that incorporates behaviour change theories such as the Theoretical Domains Framework and the Behaviour Change Wheel to elucidate specific barriers and enablers to performing renal QI-DTP interventions, as perceived by Canadian pharmacists, rather than considering a broader suite of clinical pharmacy performance indicators, such as medication reconciliation, patient education, and protocol development. Drug-related interventions such as the QI-DTP interventions cannot be effectively implemented without first determining what renal pharmacists see as barriers and enablers to performing them and then removing, modifying, or enhancing these barriers and enablers, as appropriate.

Six themes related to barriers and enablers to implementation of renal QI-DTP interventions were identified in this study, encompassing all 3 behaviour source components of the COM-B system. It is not surprising that capability was identified as both a barrier and an enabler, because a core component of capability is knowledge (or lack thereof). The well-trained renal pharmacists who participated in this study identified that improved knowledge is necessary for successful renal implementation of QI-DTP interventions. However, it was surprising that renal pharmacists did not consider the renal QI-DTP interventions to have the highest priority, despite the fact that they were developed by a panel of expert renal pharmacists using the highest-quality evidence. Perhaps this finding in itself reflects the other capability barrier, that renal pharmacists do not feel they have sufficient knowledge to perform priority interventions. Alternatively, perhaps it reflects participants' decreased motivation to perform interventions for which they do not believe they have the appropriate capability.

The opportunity-related barrier was related to limitations in pharmacists' perceived ability to perform high-priority interventions in collaboration with nephrologists. Stated differently, renal pharmacists felt that the QI-DTP interventions would not be supported by their nephrologist colleagues, who would be required to change an existing prescription to resolve the QI-DTP. These pharmacists generally viewed their role as medication advisors, with the nephrologist making the final decision to initiate or modify drug therapy for their patients. This opportunity-related barrier may also reflect a systematically different practice environment from the practice environment of the expert renal pharmacists who developed the renal QI-DTP interventions (e.g., small non-academic hospitals versus large academically affiliated institutions). Large academic institutions may have more support for continuing education and a more specialized practice, whereas community hospitals may require the renal pharmacist to cross-cover other areas, which would decrease time available to spend specifically on renal interventions. Moreover, this barrier may be related to the capability-related barrier of insufficient pharmacist knowledge or to the motivation-related barrier of perceived inability to perform these interventions. Conversely, the pharmacists who worked closely with other health care professionals on a multidisciplinary nephrology team stated that it would be relatively easy to implement these QI-DTP interventions, because they had the trust and support of the nephrologist and the nephrology team. It would be interesting to better understand nephrologists' views about this perceived opportunity barrier. 
The enablers of implementation of renal QI-DTP interventions encompassed capability, opportunity, and motivation behaviour sources. From a capability standpoint, there is potential to engage renal pharmacists with background education and training beyond that of an entry-to-practice degree to enhance the implementation of QI-DTP interventions. Opportunity can be enhanced through engagement of renal pharmacists and nephrologists to build support for implementation of renal QI-DTP interventions. In terms of motivation, it is important to note that the pharmacists who had post-entry-to-practice training (residency or PharmD) appeared to demonstrate more confidence in their ability to implement the QI-DTP interventions than the pharmacists without this level of training. The pharmacists without post-entry-to-practice training acknowledged the importance of having a set of QI-DTP interventions in renal practice and stated that if they were to receive brief education or training on the QI-DTP interventions, they would most likely be able to incorporate them into their practice. This finding suggests that additional training may be beneficial in motivating pharmacists to perform renal QI-DTP interventions. Finally, implementation of renal QI-DTP interventions may be enhanced by harnessing renal pharmacists' motivation to achieve the best possible health outcomes for their patients.

This is one of only a few studies that have attempted to identify sources of desired behaviour related to renal pharmacy professional practice, and our methods led to several strengths. The sample of renal pharmacists was heterogeneous in terms of education and training background, and we had representation from most provinces across Canada. The interview questions were developed using a validated tool for identifying factors that influence behaviour change. The investigator who performed the interviews and coding kept a reflexive journal to improve the rigour and trustworthiness of the results, through transparency about the investigator's coding process.

The limitations of this study require discussion. The study relied upon volunteer participation, which might have introduced selection bias; as a result, the themes that we identified may not be applicable to the entire community of renal pharmacists. The participants who were interviewed may represent a more motivated subgroup of renal pharmacists than the general population of renal clinical pharmacists in Canada. We did not group participants according to whether they worked at an academic-affiliated institutions or a non-academic-affiliated institution, which might have affected pharmacists' success in performing interventions. A single investigator transcribed all of the interviews and performed most of the coding, which might have affected the rigour of our findings, as other investigators might have coded responses slightly differently and might have identified different themes from the same data. Finally, despite identifying only 12 of the 14 TDF domains, it is nonetheless possible that we reached code saturation, because participants might not have perceived the 2 unidentified domains (emotion, reinforcement) as either barriers or enablers. However, it is unlikely that interviewing additional renal pharmacists would have led to these 2 TDF domains being identified as barriers or enablers, because redundant information was provided by the existing sample of participants.

Future research should focus on soliciting patient feedback on the QI-DTP interventions to determine whether patients' medication priorities align with this consensus list and to obtain feedback on how patients learn about drug therapy and what type of information patients need to make decisions about medications. The information from these future studies will be used, in part, along with the barriers and enablers identified in this study, to help inform the development of an intervention to increase the uptake of QI-DTP interventions by renal pharmacists. Other research should aim to investigate some of the social influences identified as barriers in this study, such as perceived lack of support from nephrologists; those studies should involve the specific professionals assumed to be resistant to implementation of renal QI-DTP interventions. An understanding of these views could supplement the themes identified in the current study to strengthen the design of behaviour change interventions.

Finally, but most importantly, the priority for future research will be to incorporate the results of this study into the Behaviour Change Wheel to develop, implement, and evaluate proven behaviour change interventions aimed at overcoming the identified barriers and enhancing the enablers to implementation of renal QI-DTP interventions by renal pharmacists. By understanding the factors that influence renal pharmacists' clinical behaviour, interventions can be adjusted to more effectively modify behaviour. This future research will also provide an opportunity to evaluate the feasibility and success of these interventions. The ultimate goal is to improve renal patient outcomes by optimizing the pharmaceutical care that renal pharmacists deliver.

\section{CONCLUSION}

Renal clinical pharmacists identified 3 barriers and 3 enablers to implementation of renal QI-DTP interventions. Removing or modifying the barriers and optimizing the enablers might encourage renal pharmacists to perform these high-value interventions and improve the quality of care for renal patients.

\section{References}

1. Arora P, Vasa P, Brenner D, Iglar K, McFarlane P, Morrison H, et al. Prevalence estimates of chronic kidney disease in Canada: results of a nationally representative survey. CMAJ. 2013;185(9):E417-23.

2. Manley HJ, Cannella CA, Bailie GR, St Peter WL. Medication-related problems in ambulatory hemodialysis patients: a pooled analysis. Am J Kidney Dis. 2005;46(4):669-80.

3. Cipolle RJ, Strand LM, Morley PC. Pharmaceutical care practice: the clinician's guide. McGraw-Hill Companies, Inc; 2004.

4. Raymond CB, Wazny LD, Sood AR. Standards of clinical practice for renal pharmacists. Can J Hosp Pharm. 2013;66(6):369-74. 
5. Goldstein M, Yassa T, Dacouris N, McFarlan P. Multidisciplinary predialysis care and morbidity and mortality of patients on dialysis. Am J Kidney Dis. 2004;44(4):706-14.

6. Levin A, Hemmelgarn B, Culleton B, Tobe S, McFarlane P, Ruzicka M, et al.; Canadian Society of Nephrology. Guidelines for the management of chronic kidney disease. CMAJ. 2008;179(11):1154-62.

7. Wang EH, Co M. Should there be a cap on the number of patients under the care of a clinical pharmacist? The "pro" side. Can J Hosp Pharm. 2012;65(4):319-20.

8. $\mathrm{Ng} \mathrm{J}$, Harrison J. Key performance indicators for clinical pharmacy services in New Zealand public hospitals: stakeholder perspectives. J Pharm Health Serv Res. 2010;1(2):75-84.

9. Boutin K, Nevers W, Gorman SK, Slavik RS, Martinusen DJ, Lo C. Development of intervention-related quality indicators for renal clinical pharmacists using a modified Delphi approach. Int J Pharm Pract. 2019; 27(5):436-42.

10. Minard LV, Deal H, Harrison ME, Toombs K, Neville H, Meade A. Pharmacists' perceptions of the barriers and facilitators to the implementation of clinical pharmacy key performance indicators. PLoS One. 2016; 11(4):e0152903.

11. Straus SE, Tetroe J, Graham I. Defining knowledge translation. CMAJ. 2009;181(3-4):165-8.

12. Barry AR, Loewen PS, de Lemos J, Lee KG. Reasons for non-use of proven pharmacotherapeutic interventions: systematic review and framework development. J Eval Clin Pract. 2012;18(1):49-55.

13. French SD, Green SE, O'Connor DA, McKenzie JE, Francis JJ, Michie S, et al. Developing theory-informed behaviour change interventions to implement evidence into practice: a systematic approach using the Theoretical Domains Framework. Implement Sci. 2012;7:Article 38.

14. Graham ID, Logan J, Harrison MB, Straus SE, Tetroe J, Caswell W, et al. Lost in knowledge translation: time for a map? J Contin Educ Health Prof. 2006;26(1):13-24.

15. Lee PY, Liew SM, Abdullah A, Abdullah N, Ng CJ, Hanafi NS, et al. Healthcare professionals' and policy makers' views on implementing a clinical practice guideline of hypertension management: a qualitative study. PLoS One. 2015;10(5):e0126191.

16. Bennett RE, DeHart RM, Lauderdale SA. Survey of care provided by ambulatory care pharmacists to patients with chronic kidney disease. $\mathrm{Am} \mathrm{J}$ Health Syst Pharm. 2006;63(21):2123-7.

17. Stemer G, Lemmens-Gruber R. Clinical pharmacy activities in chronic kidney disease and end-stage renal disease patients: a systematic literature review. BMC Nephrol. 2011;12(1):35.

18. Salgado TM, Moles R, Benrimoj SI, Fernandez-Llimos F. Pharmacists' interventions in the management of patients with chronic kidney disease: a systematic review. Nephrol Dial Transplant. 2012;27(1):276-92.

19. Atkins L, Francis J, Islam R, O'Connor D, Patey A, Ivers N, et al. A guide to using the Theoretical Domains Framework of behavior change to investigate implementation problems. Implement Sci. 2017;12:Article 77.

20. Cane J, O'Connor D, Michie S. Validation of the theoretical domains framework for use in behaviour change and implementation research. Implement Sci. 2012;7:Article 37.
21. Chimeddamba O, Peeters A, Ayton D, Tumenjargal E, Sodov S, Joyce C. Implementation of clinical guidelines on diabetes and hypertension in urban Mongolia: a qualitative study of primary care providers' perspectives and experiences. Implement Sci. 2015;10:Article 112.

22. Elouafkaoui P, Young L, Newlands R, Duncan EM, Elders A, Clarkson JE, et al. An audit and feedback intervention for reducing antibiotic prescribing in general dental practice: the RAPiD cluster randomised controlled trial. PLoS Med. 2016;13(8):1-19.

23. Hsieh HF, Shannon SE. Three approaches to qualitative content analysis. Qual Health Res. 2005;15(9):1277-88.

William Nevers, BSC(Pharm), ACPR, PharmD, is a Clinical Pharmacy Specialist - Critical Care and Emergency Medicine, Kelowna General Hospital, Kelowna, British Columbia.

Alice Ratcheva, BSc(Pharm), is a Pharmacy Practice Resident, Interior Health Pharmacy Practice Residency Program, Kelowna General Hospital, Kelowna, British Columbia.

Kate Boutin, BSC, BSC(Pharm), ACPR, is a Clinical Pharmacist, Pharmacy Services, Kelowna General Hospital, Kelowna, British Columbia.

Sean K Gorman, BSC(Pharm), ACPR, PharmD, is Regional Coordinator Clinical Quality and Research and Pharmacotherapeutic Specialist - Critical Care, Kelowna General Hospital, Kelowna, British Columbia; and is also a Clinical Associate Professor, Faculty of Pharmaceutical Sciences, The University of British Columbia, Vancouver, British Columbia.

Richard Slavik, BSc(Pharm), ACPR, PharmD, FCSHP, is Regional Manager, Pharmacy Professional Practice, and Pharmacotherapeutic Specialist Critical Care, Kelowna General Hospital, Kelowna, British Columbia; and is also a Clinical Professor, Faculty of Pharmaceutical Sciences, The University of British Columbia, Vancouver, British Columbia.

Natalie Lesko, BSc(Pharm), ACPR, PharmD, is a Clinical Pharmacy Specialist - Nephrology, Kelowna General Hospital, Kelowna, British Columbia.

Competing interests: None declared.

\section{Address correspondence to:}

Dr William Nevers

Kelowna General Hospital

2268 Pandosy Street

Kelowna BC V1Y 1T2

e-mail: william.nevers@interiorhealth.ca

Funding: None received.

Acknowledgements: The authors acknowledge and sincerely thank the 13 renal clinical pharmacists who participated in this study. 